\title{
Aneurysm of the aortic root and valve-sparing aortic root replacement: long-term outcomes from a single Polish center
}

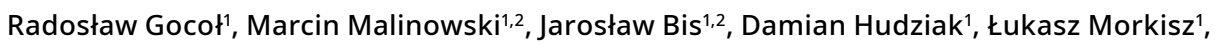 \\ Marek Elżbieciak ${ }^{3}$, Wojciech Wojakowski ${ }^{4}$, Marek A. Deja ${ }^{1,2}$ \\ 1 Department of Cardiac Surgery, Upper-Silesian Heart Center, Katowice, Poland \\ 2 Department of Cardiac Surgery, Medical University of Silesia, Faculty of Medical Sciences in Katowice, Katowice, Poland \\ 3 1st Department of Cardiology, Medical University of Silesia, Faculty of Medical Sciences in Katowice, Katowice, Poland \\ 4 3rd Division of Cardiology and Structural Heart Diseases, Medical University of Silesia, Faculty of Medical Sciences in Katowice, Katowice, Poland
}

\section{KEY WORDS}

aortic root aneurysm, aortic root remodeling, David procedure, valve-sparing aortic root replacement, Yacoub procedure
Correspondence to:

Marek A. Deja, MD, PhD, Department of Cardiac Surgery, Medical University of Silesia, ul. Ziołowa 45/47, 40-635 Katowice, Poland, phone: +48323598644 , email: mdeja@sum.edu.pl Received: June 29, 2020. Revision accepted: September 28, 2020. Published online: October 5, 2020. Kardiol Pol. 2020; 78 (12): 1235-1242 doi:10.33963/KP.15636 Copyright by the Author(s), 2020

\begin{abstract}
BACKGROUND Valve-sparing aortic root replacement (VSARR) techniques are an alternative to the classic Bentall procedure when aortic root aneurysm is not accompanied by aortic valve stenosis, and the regurgitant aortic valve is amenable to repair.

AIMS The aim of the study was to assess long-term outcomes of valve sparing aortic root replacement using the David technique and the Yacoub technique.

METHODS A total of 101 consecutive, elective VSARR procedures were performed from January 2010 to April 2020 including 52 David procedures (51.5\%) and 49 Yacoub procedures (48.5\%). We analyzed mortality, freedom from reoperation, and freedom from aortic valve regurgitation. The analysis was performed for the entire study cohort and for 2 subgroups: the David technique and the Yacoub technique.

RESULTS The mean (SD) age was 50.2 (16.1) years; 90 (89.1\%) patients were male. The median (interquartile range [IQR]) EuroScore II was 3.7 (2.7-5.8). At 1, 5, and 8 years after surgery, survival (SE) was $98 \%$ (3\%), $91.8 \%(8 \%)$, and $91.8 \%(8 \%)$, respectively, whereas freedom from reoperation (SE) was $100 \%, 97 \%$ (3\%), and $97 \%(3 \%)$, respectively. Follow-up echocardiography performed at a median (IQR) of 18.7 (2.5-36.7) months postsurgery revealed freedom from aortic valve regurgitation in $90.8 \%$ of patients. No significant differences in mortality, freedom from reoperation, and freedom from aortic valve regurgitation were noted between the David and Yacoub subgroups.
\end{abstract}

CONCLUSIONS VSARR is a safe and effective surgical technique in patients with aortic root aneurysm, as the associated mortality, reoperation rate, and aortic valve regurgitation recurrence are low.

INTRODUCTION Aortic root is the segment of the aorta between the ventricular-aortic junction and the sinotubular junction, including the aortic valve and both coronary ostia. The gold standard for surgical treatment of aortic root aneurysm is the procedure proposed by Bentall and DeBono ${ }^{1}$ in 1968, including replacement of both the aortic valve and the aortic root with reimplantation of the coronary ostia using a Dacron composite valved conduit. ${ }^{1}$ Valve-sparing aortic root replacement (VSARR) procedures provide an alternative surgical approach, particularly for younger patients, which enables replacement of the enlarged aortic root with preservation of the native aortic valve. Nowadays, 2 types of VSARR predominate in the surgical practice: aortic valve reimplantation technique introduced by David and Feindel ${ }^{2}$ in 1992 (FIGURE 1A), and aortic root remodeling technique proposed by Sarsam and Yacoub ${ }^{3}$ in 1993 (FIGURE 1B). The key difference between the 2 methods is the stabilization of the aortic annulus in the reimplantation technique. ${ }^{4}$ Both techniques 


\section{WHAT'S NEW?}

We report the largest, to the best of our knowledge, series of consecutive valve-sparing aortic root replacement procedures performed for aortic root aneurysm in a single Polish center. We analyzed the long-term survival, freedom from reoperation, and freedom from recurrent aortic valve regurgitation in 101 patients operated from January 2010 to April 2020. Additionally, we compared the outcomes of 2 approaches leading to valve sparing aortic root replacement: the David aortic valve reimplantation technique and the Yacoub aortic root remodeling technique. family, the Polish National Registry of Cardiac Surgical Procedures which contains mortality data from the Polish National Health Fund (Narodowy Fundusz Zdrowia). Death from all causes was included into the analysis.

Arterial hypertension was defined as a systolic blood pressure of $140 \mathrm{~mm} \mathrm{Hg}$ or greater, and/ or a diastolic blood pressure of $90 \mathrm{~mm} \mathrm{Hg}$ or greater, or current use of antihypertensive medications. Chronic renal failure was recorded according to the definition used in the EuroSCORE II, that is, when estimated glomerular filtration rate was lower than $85 \mathrm{ml} / \mathrm{min} / 1.73 \mathrm{~m}^{2}$. Diabetes mellitus status was recorded based on patient receiving antidiabetic medication, that is, insulin or oral antidiabetic therapy. Coronary artery disease and atrial fibrillation were defined according to the European Society of Cardiology guidelines. ${ }^{7}$ Marfan syndrome was defined according to the 1996 revised criteria. ${ }^{8}$

The local institutional review board opinion had been requested. It was decided that the follow up was not a medical experiment and therefore their approval was not required.

The echocardiographic assessment of aortic valve repair was performed based on the 4-grade scale of aortic valve regurgitation: 0 , none or trivial; 1 , mild; 2 , moderate; 3 , moderately severe; 4 , severe. ${ }^{9}$ The echocardiographic measurements were performed according to the recommendations of the Working Group on Echocardiography of the Polish Cardiac Society. ${ }^{10}$

Mortality, freedom from reoperation, and freedom from aortic valve regurgitation were analyzed in the entire cohort of patients and in 2 subgroups: patients undergoing VSARR with the David technique and those with the Yacoub technique.

Surgical technique Standard surgical access via median sternotomy was used. Cardiopulmonary bypass (CPB) was established between
A

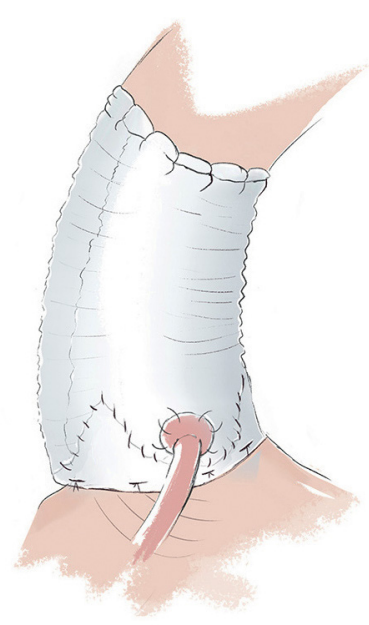

B

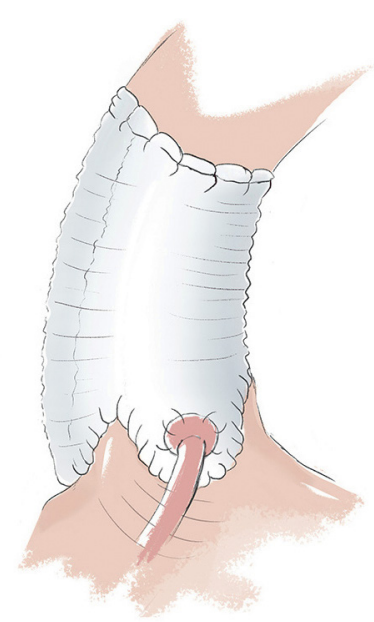



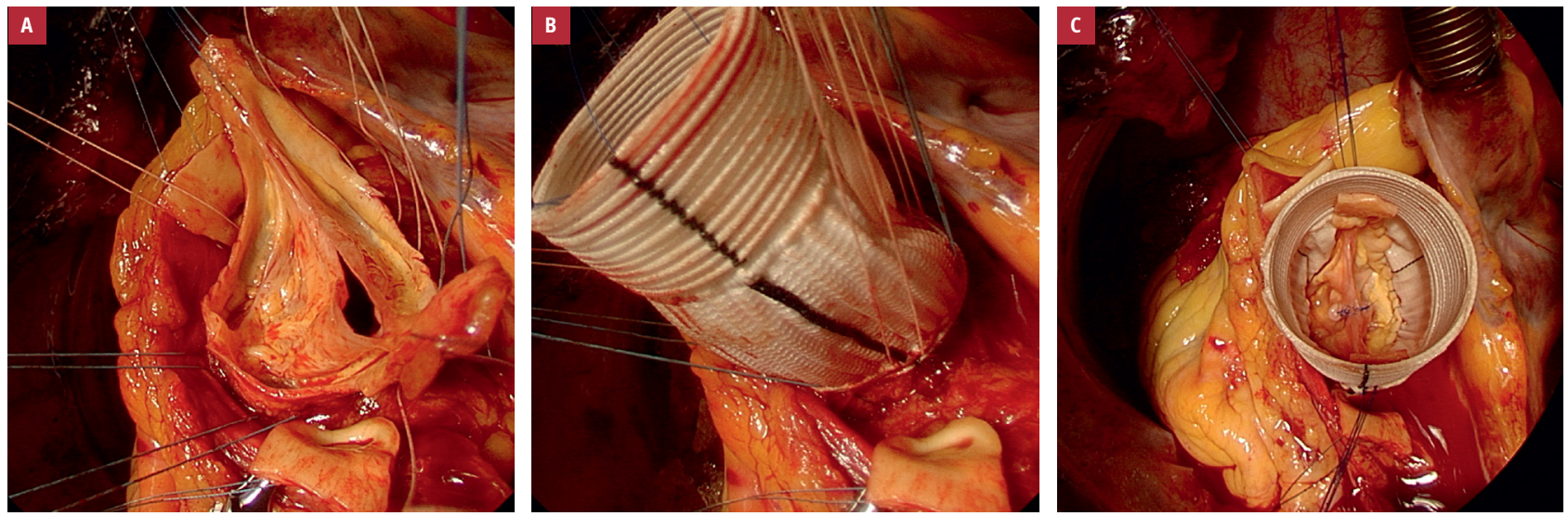

FIGURE 2 Valve-sparing aortic root replacement with the David technique; A - dissected native bicuspid aortic valve prepared for reimplantation;

B - Dacron conduit sewn into the aortic annulus; $\mathbf{C}$ - native aortic valve reimplanted into the dacron conduit

the right atrium and the ascending aorta in normothermic conditions. A vent was placed into the left ventricle through the right superior pulmonary vein for ventricular decompression. One of 3 types of cardioplegic regimens was used: cold del Nido cardioplegic solution, cold blood cardioplegic solution (ratio of 4 to 1 ), and miniplegia. Moderate hypothermia $\left(26^{\circ} \mathrm{C}\right)$ and temporary brain perfusion with continuous monitoring of cerebral oximetry were used for cerebral protection in patients undergoing surgery of the aortic arch. ${ }^{11}$ The decision about the type of VSARR performed (David or Yacoub) was left to the discretion of the operating surgeon.

For VSARR with the David technique, the aortic valve was dissected from the surrounding structures, extending below the basal aortic valve annulus. The root and ascending aorta aneurysm was resected and coronary buttons were formed. Subsequently, the aortic valve and coronary buttons were reimplanted into the Dacron conduit (FIGURE2A-2C). The conduit diameter was selected based on the measurement of the height of the left noncoronary commissure. The Schäfers caliper was used to measure the effective coaptation height of the aortic valve leaflets. Effective coaptation height of $9 \mathrm{~mm}$ was regarded as acceptable for ensuring durable repair.

When aortic valve cusps abnormalities were present, following techniques were used for cusp repair: central plication, free-edge plication with the use of a polytetrafluoroethylene (PTFE) suture, cusp shaving, and decalcification. ${ }^{12,13}$ When aneurysm of the ascending aorta or the aortic arch was present, it was excised and replaced with the Dacron aortic graft.

For VSARR with the Yacoub technique, the aortic valve was not dissected from the left ventricular outflow tract. Only the enlarged sinuses of the aortic root were excised and the coronary buttons were formed. When the diameter of the aortic annulus exceeded $28 \mathrm{~mm}$, it was stabilized with one of the following techniques: external stabilization with a PTFE suture, ${ }^{14}$ or semicircular
Dacron graft ring, ${ }^{15}$ or internal stabilization with Cabrol stitch (subcommissural plication), ${ }^{16}$ with a PTFE suture ${ }^{17}$ or rigid HAART 300 ring (BioStable Science and Engineering, Austin, Texas, United States). ${ }^{18}$ The conduit diameter was selected based on the measurement of the left noncoronary commissure height. Subsequently, a triple-tongued Dacron graft imitating the aortic root sinuses was prepared and sewn to the aortic annulus, thus reconstructing the aortic root. The coronary buttons were implanted into this reconstructed root. When aortic valve cusps abnormalities were present, they were addressed in similar fashion as in the David procedure.

Statistical analysis Data are presented as mean (SD) when normally distributed or as median with interquartile range (IQR) when normality assumptions (Shapiro-Wilk test) were not met. Categorical data are expressed as numbers and percentages. The comparisons between groups were carried out with the use of the $t$ test or the MannWhitney test when normality failed. The $\mathrm{X}^{2}$ test or the Fisher exact test was used to determine whether frequencies differed between the study groups. The Kaplan-Meier time-to-event curves were generated for the entire cohort, and the subgroups were compared with the log-rank (MantelCox) test. The 1-, 5-, and 8-year survival/freedom from reoperation was estimated and reported with SE. The statistical analysis was performed with IBM SPSS v. 26 (IBM Corp., Armonk, New York, United States). The survival analysis was done in GraphPad Prism v. 8.4 (GraphPad Software, La Jolla, California, United States). A P value of less than 0.05 was considered significant.

RESULTS A total of 101 elective VSARR procedures were performed from January 2010 to April 2020 in the Department of Cardiac Surgery in Katowice, including 52 (51.5\%) VSARR with the David procedure and 49 (48.5\%) VSARR with the Yacoub procedure. 
TABLE 1 Clinical and echocardiographic characteristics

\begin{tabular}{|c|c|c|c|c|c|}
\hline \multicolumn{2}{|l|}{ Variable } & All $(n=101)$ & David $(n=52)$ & Yacoub $(n=49)$ & $P$ value \\
\hline \multicolumn{6}{|l|}{ Clinical data } \\
\hline \multicolumn{2}{|l|}{ Male sex } & $90(89.1)$ & $48(92.3)$ & $42(85.7)$ & 0.29 \\
\hline \multicolumn{2}{|l|}{ Age, y, mean (SD) } & $50.2(16.1)$ & $42.7(15.4)$ & $58.2(12.6)$ & $<0.001$ \\
\hline \multicolumn{2}{|l|}{ Height, cm, mean (SD) } & $177.7(9.7)$ & $179.9(10.8)$ & $175.3(7.6)$ & 0.01 \\
\hline \multicolumn{2}{|l|}{ Weight, kg, mean (SD) } & $85.8(16.7)$ & $84.7(16.1)$ & $86.8(17.5)$ & 0.53 \\
\hline \multicolumn{2}{|l|}{ BMI, kg/m², mean (SD) } & $27.2(5)$ & $26.2(4.4)$ & $28.2(5.3)$ & 0.04 \\
\hline \multirow[t]{4}{*}{ NYHA } & I & $43(43.4)$ & $27(52.9)$ & $16(33.3)$ & \multirow[t]{4}{*}{0.07} \\
\hline & II & $48(48.5)$ & $19(37.3)$ & $29(60.4)$ & \\
\hline & III & $7(7.1)$ & $5(9.8)$ & $2(4.2)$ & \\
\hline & IV & $1(1)$ & 0 & $1(2.1)$ & \\
\hline \multicolumn{2}{|l|}{ BAV } & $50(39.6)$ & 27 (51.9) & $13(26.5)$ & 0.009 \\
\hline \multicolumn{2}{|l|}{ Marfan syndrome } & $18(17.8)$ & $16(30.7)$ & $2(4.1)$ & 0.001 \\
\hline \multicolumn{2}{|l|}{ Coronary artery disease } & $13(12.9)$ & $4(7.7)$ & $9(18.4)$ & 0.11 \\
\hline \multicolumn{2}{|l|}{$\begin{array}{l}\text { At least moderate mitral } \\
\text { regurgitation }\end{array}$} & $10(10.1)$ & $6(11.5)$ & $4(8.2)$ & 0.51 \\
\hline \multicolumn{2}{|l|}{$\begin{array}{l}\text { At least moderate tricuspid } \\
\text { regurgitation }\end{array}$} & $10(10.1)$ & $6(11.5)$ & $4(8.2)$ & 0.52 \\
\hline \multicolumn{2}{|l|}{ Arterial hypertension } & $72(71.3)$ & $30(57.7)$ & $42(85.7)$ & 0.002 \\
\hline \multicolumn{2}{|l|}{ Atrial fibrillation } & $11(10.9)$ & $4(7.7)$ & $7(14.3)$ & 0.28 \\
\hline \multicolumn{2}{|l|}{ Diabetes mellitus } & $6(5.9)$ & $3(5.7)$ & $3(6.1)$ & 1.0 \\
\hline \multicolumn{2}{|l|}{ Chronic renal failure } & $24(23.7)$ & $10(19.2)$ & $14(28.5)$ & 0.02 \\
\hline \multicolumn{2}{|l|}{ EUROSCORE II, median (IQR) } & $3.7(2.7-5.8)$ & $3.1(2.5-4.1)$ & $4.8(3.2-6.9)$ & $<0.001$ \\
\hline \multicolumn{6}{|c|}{ Echocardiographic data $(n=96)$} \\
\hline \multirow{5}{*}{$\begin{array}{l}\text { Aortic regurgitation grade } \\
(n=96)\end{array}$} & 0 & $10(17.2)$ & $5(10.4)$ & $5(10.4)$ & \multirow[t]{5}{*}{0.95} \\
\hline & 1 & $7(7.1)$ & $3(6.3)$ & $4(8.3)$ & \\
\hline & 2 & $14(14.1)$ & $6(12.5)$ & $8(16.7)$ & \\
\hline & 3 & $30(30.3)$ & $15(31.3)$ & $15(31.3)$ & \\
\hline & 4 & $35(37.4)$ & $19(39.6)$ & $16(33.3)$ & \\
\hline \multicolumn{2}{|c|}{ LVOT, mm, median (IQR) $(n=52)$} & $24(22-27)$ & $24(22-28)$ & $24(23-25)$ & 0.99 \\
\hline \multicolumn{2}{|c|}{ Aortic annulus, mm, median (IQR) $(n=85)$} & $27(26-30)$ & $28(27-31)$ & $27(25-28.5)$ & 0.003 \\
\hline \multicolumn{2}{|c|}{ Aortic root, mm, median (IQR) $(n=94)$} & $51(46.7-55)$ & $51.5(47-55)$ & $50(46-55)$ & 0.38 \\
\hline \multicolumn{2}{|c|}{ Ascending aorta, mm, median (IQR) $(n=92)$} & $50(45-56)$ & $48(39-54)$ & $53(48-57)$ & 0.003 \\
\hline \multicolumn{2}{|l|}{$E F, \%$, median (IQR) $(n=94)$} & $55(50-60)$ & $55(52-60)$ & $55(50-59)$ & 0.28 \\
\hline \multicolumn{2}{|l|}{ EDV, ml, median (IQR) $(n=77)$} & $194(150-245)$ & $200.5(162-250)$ & $194(147-234.5)$ & 0.44 \\
\hline \multicolumn{2}{|l|}{ ESV, ml, median (IQR) $(n=76)$} & $75.5(59-129)$ & $82(64-122)$ & $91(66-120)$ & 0.81 \\
\hline
\end{tabular}

Data are presented as number (percentage) of patients unless otherwise indicated.

Abbreviations: BAV, bicuspid aortic valve; BMI, body mass index; EDV, end diastolic volume; EF, ejection fraction; ESV, end systolic volume; IQR, interquartile range; LVOT, left ventricular outflow tract; NYHA, New York Heart Association; TAV, tricuspid aortic valve

The mean (SD) patient age was 50.2 (16.1) years, 90 (89.1\%) patients were male. The median (IQR) EuroScore II was 3.7 (2.7-5.8). The comparison of the baseline characteristics demonstrated that patients in the David subgroup were significantly younger than those in the Yacoub subgroup (42.7
[15.4] years vs 58.2 [12.6] years). Moreover, patients in the David subgroup had less comorbidities, which was reflected by lower EuroScore II comparing with the Yacoub subgroup (3.1 [2.4-4.1] vs 4.8 [3.2-6.9]; $P<0.001$ ). Detailed demographic and echocardiographic data are presented in TABLE1. 
TABLE 2 Surgery scope, data, and complications

\begin{tabular}{|c|c|c|c|c|c|}
\hline \multicolumn{2}{|l|}{ Variable } & All $(n=101)$ & David $(n=52)$ & Yacoub $(n=49)$ & $P$ value \\
\hline \multicolumn{2}{|c|}{ Aortic annuloplasty } & $15(14.8)$ & 0 & $15(30.6)$ & $<0.001$ \\
\hline \multirow{3}{*}{$\begin{array}{l}\text { External aortic } \\
\text { annuloplasty }\end{array}$} & All & $5(5)$ & 0 & $5(10.2)$ & 0.05 \\
\hline & PTFE suture & $2(2)$ & 0 & $2(4.1)$ & 0.45 \\
\hline & Semi ring & $3(3)$ & 0 & $3(6.1)$ & 0.22 \\
\hline \multirow{4}{*}{$\begin{array}{l}\text { Internal aortic } \\
\text { annuloplasty }\end{array}$} & All & $10(10)$ & 0 & $10(20.4)$ & 0.002 \\
\hline & Cabrol stitch & $6(6)$ & 0 & $6(12.2)$ & 0.03 \\
\hline & HAART 30 ring & $3(3)$ & 0 & $3(6.1)$ & 0.22 \\
\hline & PTFE suture & $1(1)$ & 0 & $1(2)$ & 0.97 \\
\hline \multirow{6}{*}{$\begin{array}{l}\text { Aortic cusp } \\
\text { correction }\end{array}$} & All & $62(61.4)$ & $31(59.6)$ & $31(63.3)$ & 0.70 \\
\hline & Central plication & $55(54.5)$ & $27(51.9)$ & $28(57.1)$ & 0.59 \\
\hline & Free edge plication & $1(1)$ & $1(1.9)$ & 0 & 1.0 \\
\hline & Resection & $7(6.9)$ & $4(7.7)$ & $3(6.1)$ & 1.0 \\
\hline & Decalcification & $5(5)$ & 0 & $5(10.2)$ & 0.02 \\
\hline & Shaving & $8(7.9)$ & $2(3.8)$ & $6(12.2)$ & 0.15 \\
\hline \multicolumn{2}{|c|}{ Ascending aorta replacement } & $101(100)$ & $52(100)$ & $49(100)$ & 1.0 \\
\hline \multicolumn{2}{|l|}{ CABG } & $13(12.9)$ & $4(7.7)$ & $9(18.4)$ & 0.14 \\
\hline \multicolumn{2}{|c|}{ Mitral valve repair } & $4(4)$ & $2(3.8)$ & $2(4.1)$ & 1.0 \\
\hline \multicolumn{2}{|c|}{ Tricuspid valve repair } & $1(1)$ & 0 & $1(2)$ & 0.48 \\
\hline \multicolumn{2}{|l|}{$X$-clamp, $\min$} & $121(98-137.5)$ & $133.5(120.2-143.7)$ & $103(84-120.5)$ & $<0.001$ \\
\hline \multicolumn{2}{|l|}{$\mathrm{CPB}, \min$} & $146(121.5-165.5)$ & $156(138.5-171.2)$ & $123(105.5-150)$ & $<0.001$ \\
\hline \multicolumn{2}{|l|}{ Death } & $3(3)$ & $1(1.9)$ & $2(4.1)$ & 0.96 \\
\hline \multicolumn{2}{|l|}{ Drainage, $\mathrm{ml}$} & $705(550-950)$ & $750(600-1085)$ & $702.5(535-860)$ & 0.25 \\
\hline \multicolumn{2}{|c|}{ Ventilation time, $\mathrm{h}$} & $12.9(10.8-19)$ & $12.6(10.7-20.9)$ & $13.4(10.4-17.9)$ & 0.94 \\
\hline \multicolumn{2}{|l|}{ Hospital stay, d } & $8(7-10)$ & $8(7-10)$ & $8(7-10.75)$ & 0.55 \\
\hline \multicolumn{2}{|c|}{ Resternotomy for bleeding } & $13(15.1)$ & $8(18.6)$ & $5(11.6)$ & 0.36 \\
\hline \multicolumn{2}{|c|}{ Cardiac tamponade } & $3(3)$ & $1(1.9)$ & $2(4.1)$ & 0.61 \\
\hline \multicolumn{2}{|l|}{ Stroke } & $2(2)$ & $1(1.9)$ & $1(2.0)$ & 1.0 \\
\hline \multicolumn{2}{|l|}{ Renal failure } & $1(1)$ & 0 & $1(2)$ & 0.97 \\
\hline \multicolumn{2}{|l|}{ Pneumonia } & $4(4)$ & 0 & $4(8.2)$ & 0.03 \\
\hline \multicolumn{2}{|l|}{ Wound infection } & $1(1)$ & $1(1.9)$ & 0 & 1.0 \\
\hline \multicolumn{2}{|c|}{ Permanent pacemaker implantation } & $4(4)$ & $3(5.8)$ & $1(2)$ & 0.61 \\
\hline
\end{tabular}

Data are presented as number (percentage) of patients or median (interquartile range).

Abbreviations: CABG, coronary artery bypass graft; CPB, cardiopulmonary bypass; ICU, intensive care unit; PTFE, polytetrafluoroethylene

The median (IQR) diameter of the Dacron conduit used was $32 \mathrm{~mm}$ (30-34) for the David procedure and $30 \mathrm{~mm}$ (30-32) for the Yacoub procedure $(P=0.21)$ (TABLE2).

In 15 patients (30.6\%) from the Yacoub subgroup, basal aortic annulus stabilization was performed (TABLE2).

In both VSARR subgroups aortic valve cusps repair was performed in more than $60 \%$ of patients $(P=0.70)$, and the most frequently implemented repair technique was central plication (TABLE2).

Perioperative mortality (<30 days) in the entire study cohort was $3 \%$ (1 death [1.9\%] in the David group and 2 deaths [4.1\%] in the Yacoub group; $P=0.62)$, and median hospitalization stay after surgery was 8 (7-10) days. Most frequent postoperative complication was bleeding requiring chest re-exploration which occurred in 13 patients (15.1\%). Detailed perioperative data are presented in TABLE2. 


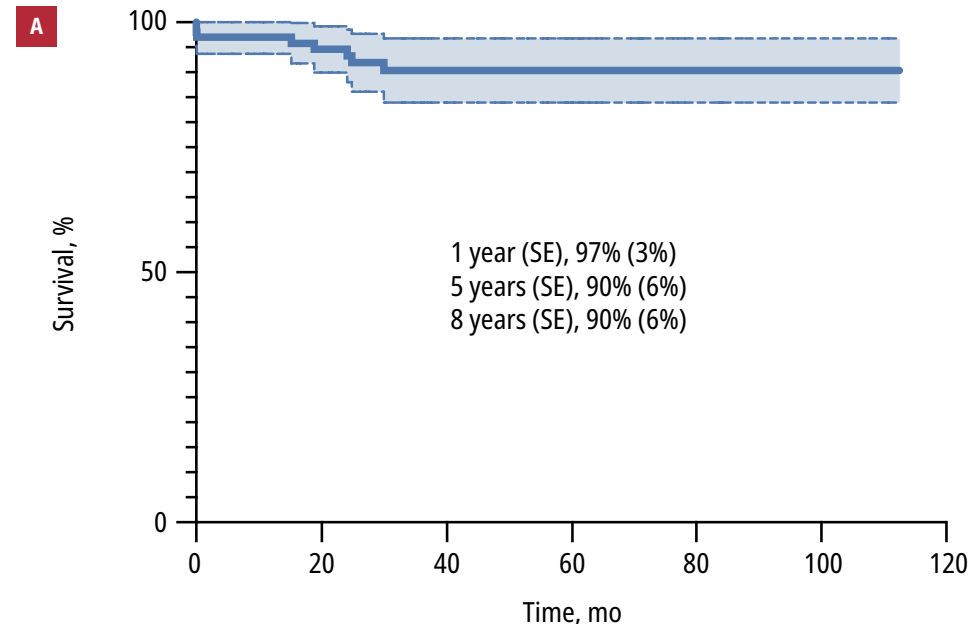

Patients at risk:

$\begin{array}{llllllll}101 & 77 & 47 & 32 & 14 & 5 & 1\end{array}$

B

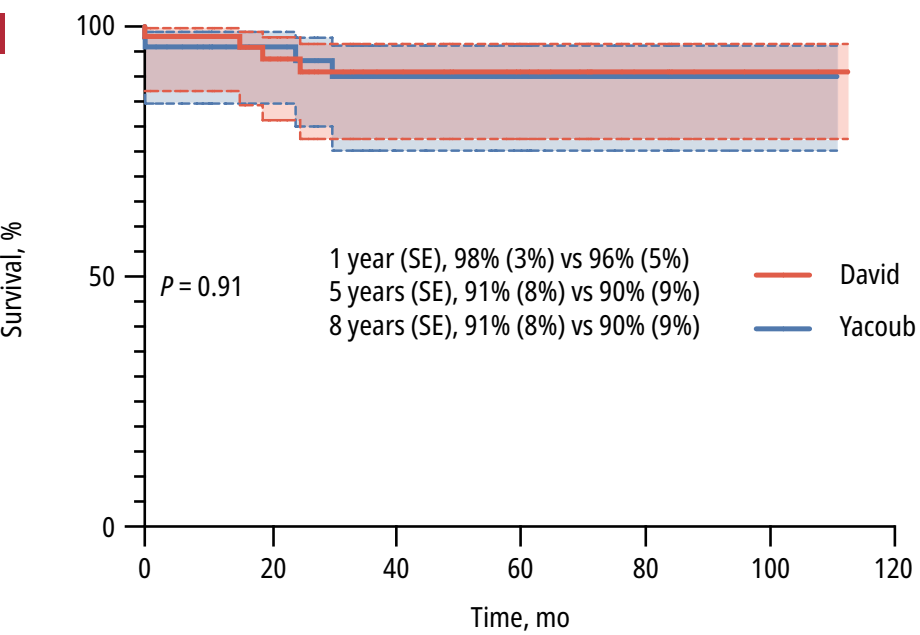

Patients at risk:

$\begin{array}{lllllll}52 & 41 & 26 & 20 & 9 & 4 & 1 \\ 49 & 37 & 22 & 13 & 6 & 2 & 1\end{array}$

FIGURE 3 Kaplan-Meier survival curves with 95\% CI; A - all patients; B - comparison of patients with the David and Yacoub procedures. The subgroups in panel B were compared with the log-rank (Mantel-Cox) test.

The comparison of perioperative data demonstrated a significantly longer $\mathrm{CPB}$ time in the $\mathrm{Da}$ vid than in the Yacoub group (median [IQR], 156 [138.5-171.2] minutes vs 123 [105.5-150] minutes; $P<0.001)$. A similar relationship between those groups was noted with regard to aortic X-clamp time (median [IQR], 133.5 [120.2-143.7] minutes vs 103 [84-120.5] minutes; $P<0.001$; TABLE2).

The ratio of postoperative complications was similar in both study subgroups, with the only exception of postoperative respiratory failure, which occurred more frequently in the Yacoub subgroup than in the David subgroup ( $8.2 \%$ vs $0 \% ; P=0.03$ ) (TABLE2).

Our analysis includes follow-up data on mortality and freedom from reoperation from all patients, and echocardiographic data on freedom from aortic valve regurgitation recurrence from
99\% of patients (96.2\% from the David subgroup and $100 \%$ from the Yacoub subgroup; $P=0.33$ ).

Five patients died during the follow-up period, which translates into 1-year Kaplan-Meier survival (SE) of $97 \%$ (3\%), and 5- and 8-year survival (SE) of $90 \%$ (6\%) (Figure 3A).

Three (5.8\%) deaths were noted in the David subgroup during follow-up. One-year KaplanMeier survival rate (SE) was $98 \%$ (3\%), and 5- and 8-year survival rates (SE) were 91\% (8\%) (FIGUREзB).

In the Yacoub group, 2 deaths (4.1\%) occurred during follow-up. The 1-year Kaplan-Meier survival rate (SE) was $96 \%$ (5\%), and 5- and 8-year survival rates (SE) were $90 \%$ (9\%) (FIGURE3B). Mortality in both groups was similar (log rank test, $P=0.91$ ) (Figure 3B).

During follow-up, only 2 patients (2\%) underwent reoperation for recurrence of aortic valve regurgitation. Both initially had the David procedure; in one of them, the repeat repair procedure was successful, while the second underwent aortic valve replacement with mechanical prosthesis. The 1-year estimated Kaplan-Meier freedom from reoperation (SE) was 100\%, and 5and 8-year freedom (SE) was 97\% (3\%) (FIGURE 4A). In the David subgroup, 1-year estimated Kaplan-Meier freedom from reoperation (SE) was $100 \%$, and 5- and 8-year freedom (SE) was $95 \%$ (5\%) (FIGURE 4B). In the Yacoub subgroup, 1-year and 8-year estimated Kaplan-Meier freedom from reoperation (SE) was $100 \%$ (FIGURE 4B). Freedom from reoperation was similar in both subgroups (log rank test, $P=0.18$; FiguRE $4 \mathrm{~B}$ ). There were no cases of infective endocarditis in any of the operated patients during the follow-up period.

Follow-up echocardiography was performed in 99 patients (98\%) at a median (IQR) of 18.7 months (2.5-36.7) post surgery. At follow-up echocardiography, 89 patients $(90.8 \%)$ were free from aortic valve regurgitation; in the David subgroup, it was $82 \%$, and in the Yacoub subgroup, 95.9\% $(P=0.09)$ (FiguRE 5 ).

DISCUSSION VSARRs are techniques which can be regarded as an alternative to the classic Bentall procedure, but only when the aortic root aneurysm is not accompanied by aortic valve stenosis, and the regurgitant aortic valve is amenable to repair. ${ }^{2}$

Over the last 10 years, 358 elective aortic root surgeries were performed at our institution, including 257 Bentall procedures (72\%) and 101 VSARR procedures (28\%). The decision to undertake a reconstructive surgery of the aortic root (VSARR) was left at the discretion of the operating surgeon. In total, 3 surgeons were performing VSARR procedures during the study period. Patients in whom the aortic valve was not amenable to repair were excluded from reconstructive surgery. The most frequently found conditions precluding aortic valve repair were 


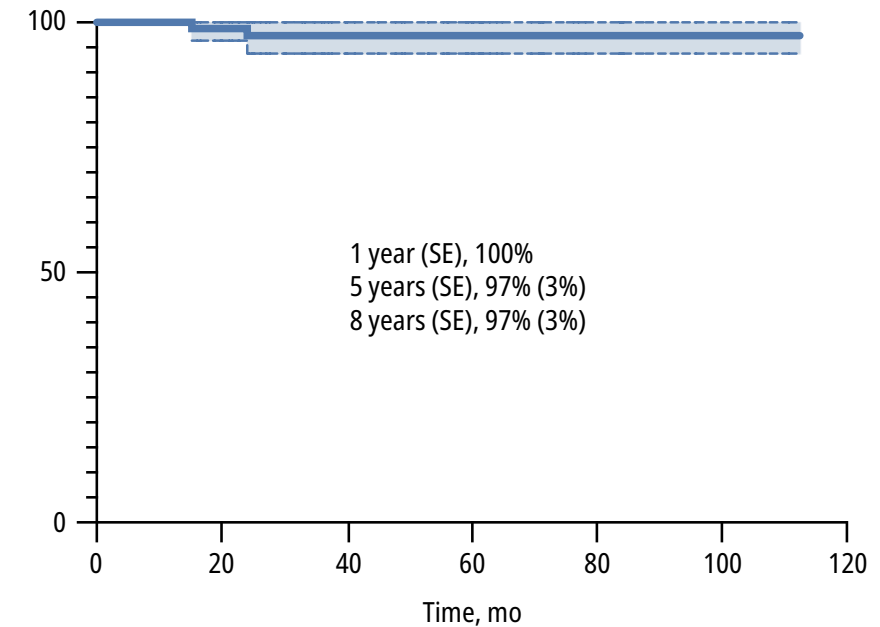

Patients at risk:

$101 \quad 77$

47

32

14

5

1

B

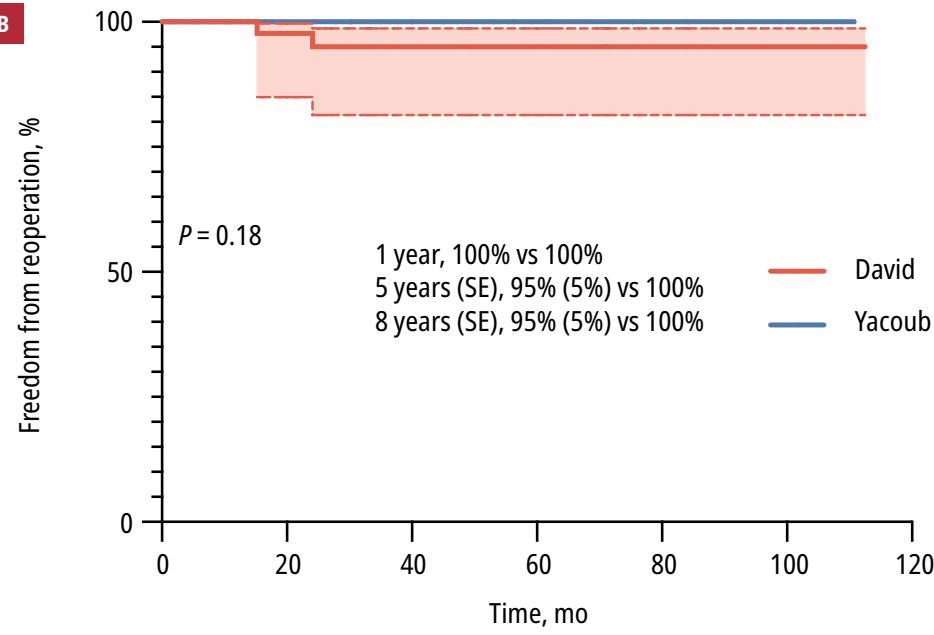

Patients at risk:

$\begin{array}{lllllll}52 & 41 & 26 & 20 & 9 & 4 & 1 \\ 49 & 37 & 22 & 13 & 6 & 2 & 1\end{array}$

FIGURE 4 Kaplan-Meier freedom from reoperation curves with 95\% CI; A - all patients; B - comparison of the David and Yacoub procedures. The subgroups in panel B were compared with the log-rank (Mantel-Cox) test.

cusp abnormalities such as calcifications, fibrosis or perforations / fenestrations.

During this time, a total of 101 such operations were performed, split almost equally between the David (52 patients) and the Yacoub technique (49 patients). To the best of our knowledge, this is the largest report to date with a long-term and near complete follow-up on VSARR outcomes in Poland.

Following recommendations from available references, we performed the David procedure more frequently in patients with Marfan syndrome and in those with bicuspid aortic valve. ${ }^{19}$ According to previously published data, late failure of the Yacoub procedure may be attributable to lack of aortic annulus stabilization. ${ }^{20}$ To eliminate this problem, we performed the aortic annulus stabilization procedure in as many as $30 \%$ of patients with a substantially enlarged aortic annulus.

Meticulous procedure planning, systematic analysis of outcomes, and a limited number of surgeons performing VSARR enabled us to achieve excellent outcomes, comparable to those reported by other authors, as described below. Our early mortality of $3 \%$ is no different to the $0 \%$ to $6 \%$ range reported by Tian et $\mathrm{al}^{21}$ in their metaanalysis including 392 publications and 1338 patients. Similarly to the metaanalysis including 672 patients published by Liu et al, ${ }^{22}$ we did not observe differences in mortality between the David and Yacoub procedures. While early mortality was numerically (not significantly) higher in the Yacoub procedure, it seems to reflect higher EuroSCORE II in this subgroup. The long-term survival was good and similar in both groups. This underscores the assumption that the EuroSCORE is predictive of short-term mortality rather than long-term survival. One, 5-, and 8-year estimated survival ratios (SE) of $98 \%$ (3\%), $91 \%$ (8\%), and $91 \%(8 \%)$ is in line with the survival ratios reported by Shrestha et al: ${ }^{23}$ $99 \%, 94 \%$, and $85 \%$, respectively.

One- and 8-year freedom from reoperation (SE) of $100 \%$ and $97 \%$ (3\%) is identical with data published by Kremer et al: ${ }^{24} 100 \%$ and $97.7 \%$ respectively.

Our analysis showed particularly good results of the Yacoub procedure with $100 \%$ freedom from reoperation and very small ratio of aortic valve regurgitation recurrence (4.1\%). These excellent outcomes can be explained by the fact that most patients undergoing the Yacoub procedure had tricuspid aortic valve (73.5\%), which is easier to repair in comparison to bicuspid aortic valve.

Arabkhani et al, ${ }^{25}$ in their meta-analysis including 4777 patients undergoing VSARR, did not find differences in mortality and reoperation rate between the David and the Yacoub procedure. Our analysis also failed to demonstrate differences between the 2 VSARR techniques with regard to mortality (log rank test $P=0.91$ ) and reoperation ratio (log-rank test $P=0.18$ ).

Our report shows that the David procedure is more technically demanding and time consuming in comparison with the Yacoub procedure, which is reflected by longer CPB and $\mathrm{X}$-clamp times. The reason is twofold: firstly, the David technique requires careful dissection of the aortic valve from the left ventricular outflow tract, and secondly, the aortic valve has to be re-implanted into the Dacron conduit with 2 layers of sutures, one under the aortic valve cusps along the aortic annulus to anchor the conduit in the left ventricular outflow tract, and one hemostatic along the base of cusps to anchor the aortic valve in the conduit.

This analysis demonstrates that VSARR are safe and effective procedures for surgical treatment of aortic root aneurysm, associated with 


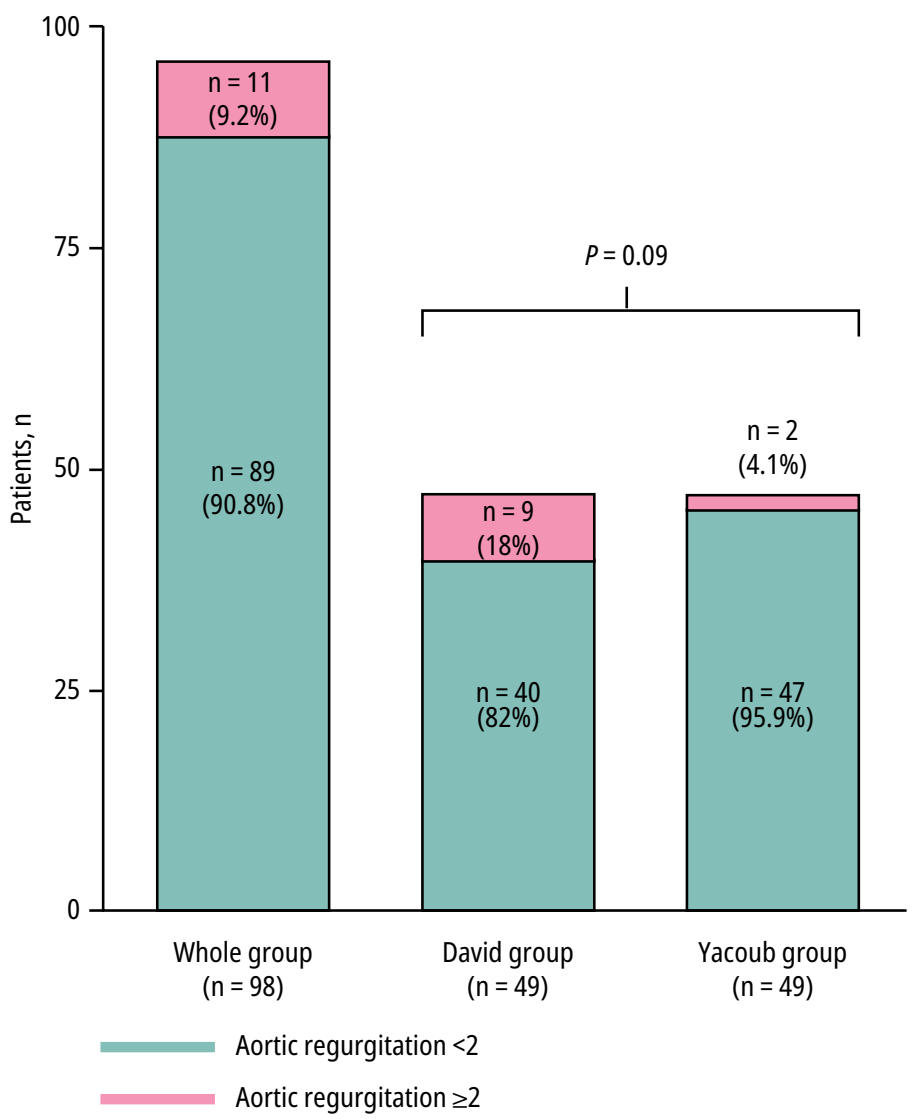

FIGURE 5 Freedom from aortic regurgitation in the whole study group and subgroups

very low perioperative morbidity. This is confirmed by low mortality, low reoperation rate, and a small number of patients with recurrence of aortic valve regurgitation. The direct comparison failed to show superiority of any of the 2 VSARR techniques (David and Yacoub). It seems that they can be used interchangeably, especially if the Yacoub procedure is supplemented with basal aortic annuloplasty.

Conclusions VSARR is a safe and effective method for surgical treatment of aortic root aneurysm. It is associated with low mortality, low reoperation rate, and small number of patients with recurrence of aortic valve regurgitation.

During up to 10-year long postoperative follow-up, there are no differences in mortality, freedom from reoperation, and freedom from aortic valve regurgitation recurrence between the David technique and the Yacoub technique for VSARR.

\section{ARTICLE INFORMATION}

\section{CONFLICT OF INTEREST None declared}

OPEN ACCESS This is an Open Access article distributed under the terms of the Creative Commons Attribution-NonCommercial-NoDerivatives 4.0 International License (CC BY-NC-ND 4.0), allowing third parties to download articles and share them with others, provided the original work is properly cited, not changed in any way, distributed under the same license, and used for noncommercial purposes only. For commercial use, please contact the journal office at kardiologiapolska@ptkardio.pl.

HOW TO CITE GocołR, Malinowski M, Bis 」, et al. Aneurysm of the aortic root and valve-sparing aortic root replacement: long-term outcomes from a single Polish center. Kardiol Pol. 2020; 78: 1235-1242. doi:10.33963/KP.15636

\section{REFERENCES}

1 Bentall HH, DeBono A. A technique for complete replacement of the ascending aorta. Thorax. 1968; 23: 338-339.

2 David TE, Feindel $\mathrm{CM}$. An aortic valve-sparing operation for patients with aortic incompetence and aneurysm of the ascending aorta. J Thorac Cardiovasc Surg. 1992; 103: 617-621.

3 Sarsam MA, Yacoub M. Remodeling of the aortic valve anulus. J Thorac Cardiovasc Surg. 1993; 105: 435-438.

4 David TE, Feindel $\mathrm{CM}$, Bos J. Repair of the aortic valve in patients with aortic insufficiency and aortic root aneurysm. J Thorac Cardiovasc Surg. 1995; 109: 345-351.

5 David TE. Aortic valve sparing operations: outcomes at 20 years. Ann Cardiothorac Surg. 2013; 2: 24-29.

6 Falk V, Baumgartner H, Bax IJ, et al. 2017 ESC/EACTS Guidelines for the management of valvular heart disease: the Task Force for the Management of Valvular Heart Disease of the European Society of Cardiology (ESC) and the European Association for Cardio-Thoracic Surgery (EACTS). Eur J Cardiothorac Surg. 2017; 52: 616-664.

7 Calkins H, Hindricks G, Cappato R, et al. 2017 HRS/EHRA/ECAS/APHRS/SOLAECE expert consensus statement on catheter and surgical ablation of atrial fibrillation: executive summary. Europace. 2018; 20: 157-208.

8 De Paepe A, Devereux RB, Dietz HC, et al. Revised diagnostic criteria for the Marfan syndrome. Am J Med Genet. 1996; 62: 417-426.

9 Zoghbi WA, Adams D, Bonow RO, et al. Recommendations for noninvasive evaluation of native valvular regurgitation: a report from the American society of echocardiography developed in collaboration with the society for cardiovascular magnetic resonance. J Am Soc Echocardiogr. 2017; 30: 303-371.

10 Lipiec $P, B a k$ J, Braksator W, et al. Transesophageal echocardiography in adults - guidelines of the Working Group on Echocardiography of the Polish Cardiac Society [in Polish]. Kardiol Pol. 2018; 76: 494-498.

11 Tan ST. Cerebral oximetry in cardiac surgery. Hong Kong Med J. 2008; 14 : 220-225.

12 Korniva T. Aortic valve repair update. Gen Thorac Cardiovasc Surg. 2015; 63: 309-319.

13 Urbanski PP. Repair of the calcified bicuspid aortic valve. Eur J Cardiothorac Surg. 2011; 39: 603-604.

14 Schneider U, Aicher D, Miura Z, Schäfers HJ. Suture annuloplasty in aortic valve repair. Ann Thorac Surg. 2016; 110: 783-785.

15 Lansac E, Di Centa I, Sleilaty G, et al. Remodeling root repair with an external aortic ring annuloplasty. J Thorac Cardiovasc Surg. 2017; 153: 1033-1042.

16 Cabrol C, Cabrol A, Guiraudon G, Bertrand M. Treatment of aortic insufficiency by means of aortic annuloplasty. Arch Mal Coeur Vaiss. 1966; 59: 1305-1312.

17 Schöllhorn J, Rylski B, Beyersdorf F. Aortic valve annuloplasty: new single suture technique. Ann Thorac Surg. 2014; 97: 2211-2213.

18 Gocoł R, Jasiński M, Hudziak D, et al. Surgical correction of aortic regurgitation using a HAART $300^{\mathrm{TM}}$ rigid aortic ring: a novel method to standardize aortic valve repair. Cardiol J. 2019; 26: 799-801.

19 Klotz $\mathrm{S}$, Stock S, Sievers $\mathrm{HH}$, et al. Survival and reoperation pattern after 20 years of experience with aortic valve-sparing root replacement in patients with tricuspid and bicuspid valves. J Thorac Cardiovasc Surg. 2018; 155: 1403-1411.

20 David TE, Feindel CM, David CM, Manlhiot C. A quarter of a century of experience with aortic valve-sparing operations. J Thorac Cardiovasc Surg. 2014; 148: 872-879.

21 Tian D, Rahnavardi M, Yan TD. Aortic valve sparing operations in aortic root aneurysms: remodeling or reimplantation? Ann Cardiothorac Surg. 2013; 2: 44-52. 22 Liu L, Wang W, Wang $X$, et al. Reimplantation versus remodeling: a meta-analysis. J Card Surg. 2011; 26: 82-87.

23 Shrestha ML, Beckmann E, Abd Alhadi F, et al. Elective David I Procedure has excellent long-term results: 20-year single-center experience. Ann Thorac Surg. 2018; 105: 731-738.

24 Kremer J, Farag M, Zaradzki M, et al. The reimplantation valve-sparing aortic root replacement technique for patients with Marfan syndrome: a single-center experience. Sci Rep. 2019; 9: 12021.

25 Arabkhani B, Mookhoek A, Di Centa I, et al. Reported outcome after valve-sparing aortic root replacement for aortic root aneurysm: a systematic review and meta-analysis. Ann Thorac Surg. 2015; 100: 1126-1131. 